\title{
From the National Perinatal Information Center: World Mental Health Day: Embracing Maternal Mental Health within a Pandemic
}

Elizabeth Rochin, PhD, RN, NE-BC

The National Perinatal Information Center (NPIC) is driven by data, collaboration and research to strengthen, connect and empower our shared purpose of improving patient care.

For over 30 years, NPIC has worked with hospitals, public and private entities, patient safety organizations, insurers and researchers to collect and interpret the data that drives better outcomes for mothers and newborns.

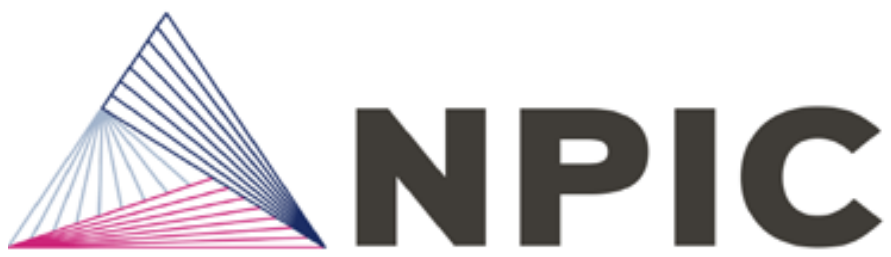

National Perinatal Information Center

"'I remember having a discussion with [my wife] a week before when she came out of a fog, and she said 'I can't control my own thoughts and I hate it. I want to be myself again. I'm lost.' That next week, my wife committed suicide. Our baby was three months old, and I was devastated. Postpartum depression is real. Education is so important, and making these women feel safe to reach out, and that people will listen, is important. '-R.M., 2016"

Stigma: (noun) Association of disgrace or public disapproval with something, such as an action or condition (1)

"I remember having a discussion with [my wife] a week before when she came out of a fog, and she said 'I can't control my own thoughts and I hate it. I want to be myself again. I'm lost.' That next week, my wife committed suicide. Our baby was three months old, and I was devastated. Postpartum depression is real. Education is so important, and making these women feel safe to reach out, and that people will listen, is important."-R.M., 2016

"October 10th each year is recognized throughout the globe as World Mental Health Day. The overall objective of World Mental Health Day is to raise awareness of mental health issues worldwide and mobilize efforts in support of mental health (2)."

October $10^{\text {th }}$ each year is recognized throughout the globe as World Mental Health Day. The overall objective of World Mental Health Day is to raise awareness of mental health issues worldwide and mobilize efforts in support of mental health (2). Recently fourteen state maternal mortality review committees (MMRC) reviewed 421 deaths and found $11 \%$ of these deaths were due to mental health conditions (3). Within the COVID-19 pandemic, mental health care and resources have become a priority through the lenses of isolation, fear, and the unknown, particularly surrounding pregnancy and the postpartum period. Pregnant and postpartum women may self-impose more severe social distancing practices that inherently conflict with behavioral activation and other standard-of-care interventions for depression and anxiety (4). Even in low-risk populations, pregnant women assessed during the COVID-19 pandemic showed higher depressive and anxiety symptoms than a separate cohort of pregnant women assessed prior to the pandemic; widespread concern has been verbalized that the pandemic will be increase disparities in mental health treatment (5).

NPIC Database Exploration/Maternal Mental Health

In May 2021, The National Perinatal Information Center (NPIC) focused on maternal mental health, specifically through the lens of substance use disorder (SUD) and neonatal abstinence syndrome (NAS). NPIC has not historically reported on the more comprehensive data collected related to maternal mental health. However, as conversations continue to generate accelerated importance and engagement in this space, providing meaningful information at the hospital level as well as the aggregate will be helpful to contribute to both the local and national discourse on the impact of maternal mental health and continue to normalize those discussions. NPIC utilized the Perinatal Center Database for the

NEONATOLOGY TODAY is interested in publishing manuscripts from Neonatologists, Fellows, NNPs and those involved in caring for neonates on case studies, research results, hospital news, meeting announcements, and other pertinent topics.

Please submit your manuscript to: LomaLindaPublishingCompany@gmail.com 
Table 1. ICD-10 Mental disorders and diseases of the nervous system complicating pregnancy, childbirth, and the puerperium. Centers for Disease Control, National Center for Health Statistics, ICD-10-CM

\begin{tabular}{|l|l|}
\hline 099.3 & $\begin{array}{l}\text { Mental disorders and diseases of the nervous system complicating pregnancy, childbirth, and } \\
\text { the puerperium }\end{array}$ \\
\hline 099.31 & Alcohol use complicating pregnancy, childbirth, and the puerperium \\
\hline 099.32 & Drug use complicating pregnancy, childbirth, and the puerperium \\
\hline 099.34 & Other mental disorders complicating pregnancy, childbirth, and the puerperium \\
\hline 099.35 & Diseases of the nervous system complicating pregnancy, childbirth, and the puerperium \\
\hline
\end{tabular}

Table 2. ICD-10 Mental and behavioral disorders associated with the puerperium, not elsewhere classified. Centers for Disease Control, National Center for Health Statistics, ICD-10-CM

\begin{tabular}{|l|l|}
\hline F53 & Mental and behavioral disorders associated with the PUERPERIUM; not elsewhere classified \\
\hline F53.0 & Postpartum depression \\
\hline F53.1 & Puerperal psychosis \\
\hline
\end{tabular}

Table 3. National Perinatal Information Center Perinatal Center Database 04/01/2020 - 03/31/2021

ICD-10-CM Coding Overview $n=334,402$

\begin{tabular}{|l|l|l|l|}
\hline ICD-10-CM Diagnosis Codes & Numerator & $\%$ \\
\hline O99.3x & Cases with one or more o99.3x diagnosis code & 55,018 & $16.5 \%$ \\
\hline O99.31 & Alcohol use complicating pregnancy, childbirth, and the puerperium & 444 & $0.1 \%$ \\
\hline O99.32 & Drug use complicating pregnancy, childbirth, and the puerperium & 8,489 & $2.5 \%$ \\
\hline O99.33 & Tobacco use disorder complicating pregnancy, childbirth, and the puerperium & 11,048 & $3.3 \%$ \\
\hline O99.34 & Other mental disorders complicating pregnancy, childbirth, and the puerperium & 38,144 & $11.4 \%$ \\
\hline O99.35 & Diseases of the nervous system complicating pregnancy, childbirth, and the puerperium & 9,591 & $2.9 \%$ \\
\hline F53x & Cases with one or more F53x codes & 451 & $0.1 \%$ \\
\hline F53.0 & Postpartum depression & 430 & $0.1 \%$ \\
\hline F53.1 & $\begin{array}{l}\text { Puerperal psychosis } \\
\text { (Rounded to one (1) decimal place) }\end{array}$ & 24 & $0.0 \%$ \\
\hline
\end{tabular}

period 04/01/2020 - 03/31/2021 to review the current landscape of mental health documentation and coding within this national database. This exploratory overview included all MDC-14 discharges (antepartum, deliveries, postpartum, $n=334,402$ ). Tables 1 and 2 , respectively, note the ICD-10 classifications utilized for this exploratory data review.

The NPIC Perinatal Database cohort provides an illustrative sample of maternal health diagnoses within a multistate sample during the COVID-19 pandemic. It is also important to note that this information depends on coding and documentation at the hospital level and may have limitations. In addition, researchers have questioned current classifications of perinatal mental health disorders and whether these disorders are unique in terms of their causes and psychopathology in pregnancy, or the same as mental disorders at other times of a woman's life (6).

\section{Discussion}

It has been estimated that, for each woman requiring psychiatric admission following birth, 2.5 require outpatient treatment, and 12 receive pharmacological treatment in primary care(7). Understanding the structural, social, and community barriers to obtaining maternal mental health treatment is an essential exercise that must be performed by hospitals and healthcare organizations routinely. Identification of maternal mental health disorders without proper referral and treatment options and availability is of tremendous concern. Depression and anxiety affect one in seven women 
during the perinatal period and are associated with increased risk of preterm delivery, reduced mother-infant bonding, and delays in cognitive/emotional development of the infant, which may persist into childhood(8). Psychiatric and mental health care availability and access can be challenging and, in some cases, completely absent, depending upon location, geography, payer source, and availability of skilled and competent providers. This becomes even more challenging for a mother navigating a NICU admission, exacerbating mental health issues and additional stressors. This is also particularly evident with women who lose insurance coverage between pregnancy and the postpartum period. In a multistate cohort of women who reported needing mental health care and had become uninsured after pregnancy, $61.1 \%$ of the uninsured $(n=66$ of 108$)$ vs. $27.1 \%$ of the insured ( $n=49$ of 181) reported an inability to obtain mental health care(9). It cannot be overstated the issues of inequity and access for women of color(10), including a statewide study that revealed particularly low mental health treatment initiation rates in Black women (4\%) and Latinas (5\%), as compared to white women ( $9 \%$ ) within six months of delivery(11). Maternal mental health awareness, access, and advocacy must remain a focal point of the healthcare discussion. Ending the stigma of mental health and mental illness is one of many steps required to assure proper screening, identification, and treatment.

The NPIC Perinatal Center Database findings for the aforementioned period include the date range within the COVID-19 pandemic. NPIC will continue to track this data and share the findings to inform regional and national discussions that can improve and enhance the care of women, and subsequently their newborns, their families, and their communities, both during and after a pandemic.

\section{References:}

1. Ahmedani BK. Mental Health Stigma: Society, Individuals, and the Profession. J Soc Work Values Ethics. 2011;8(2):41-4-16.

2. World Health Organization (2021). World mental health day. https://www. who.int/campaigns/world-mental-health-day

3. Trost SL, Beauregard JL, Smoots AN, et al. Preventing Pregnancy-Related Mental Health Deaths: Insights From 14 US Maternal Mortality Review Committees, 2008-17. Health Affairs. 2021;40(10):1551-1559. doi:10.1377/ hlthaff.2021.00615

4. Hermann A, Fitelson EM, Bergink V. Meeting Maternal Mental Health Needs During the COVID-19 Pandemic. JAMA Psychiatry. 2021;78(2):123-124. doi:10.1001/jamapsychiatry.2020.1947

5. Perzow SED, Hennessey E-MP, Hoffman MC, Grote NK, Davis EP, Hankin BL. Mental health of pregnant and postpartum women in response to the COVID-19 pandemic. J Affect Disord Rep. 2021;4:100123. doi:10.1016/j.jadr.2021.100123

6. Howard LM, Khalifeh $H$. Perinatal mental health: a review of progress and challenges. World Psychiatry. 2020;19(3):313327. doi:10.1002/wps. 20769

7. Munk-Olsen T, Maegbaek ML, Johannsen BM, et al. Perinatal psychiatric episodes: a population-based study on treatment incidence and prevalence. Transl Psychiatry. 2016;6(10):e919. doi:10.1038/tp.2016.190

8. Davenport MH, Meyer S, Meah VL, Strynadka MC, Khurana R. Moms Are Not OK: COVID-19 and Maternal Mental Health. Frontiers in Global Women's Health. 2020;1:1. doi:10.3389/fgwh.2020.00001
9. Bobo WV, Wollan P, Lewis $G$, et al. Depressive symptoms and access to mental health care in women screened for postpartum depression who lose health insurance coverage after delivery: findings from the Translating Research into Practice for Postpartum Depression (TRIPPD) effectiveness study. Mayo Clin Proc. 2014;89(9):1220-1228. doi:10.1016/j. mayocp. 2014.05.011

10. Howell EA, Mora PA, Horowitz CR, Leventhal H. Racial and ethnic differences in factors associated with early postpartum depressive symptoms. Obstet Gynecol. 2005;105(6):14421450. doi:10.1097/01.AOG.0000164050.34126.37

11. Kozhimannil KB, Trinacty $C M$, Busch $A B$, Huskamp $H A$, Adams AS. Racial and Ethnic Disparities in Postpartum Depression Care Among Low-Income Women. Psychiatr Serv. 2011;62(6):619-625. doi:10.1176/appi.ps.62.6.619

The author has no conflicts of interests to disclose.

\section{NT}
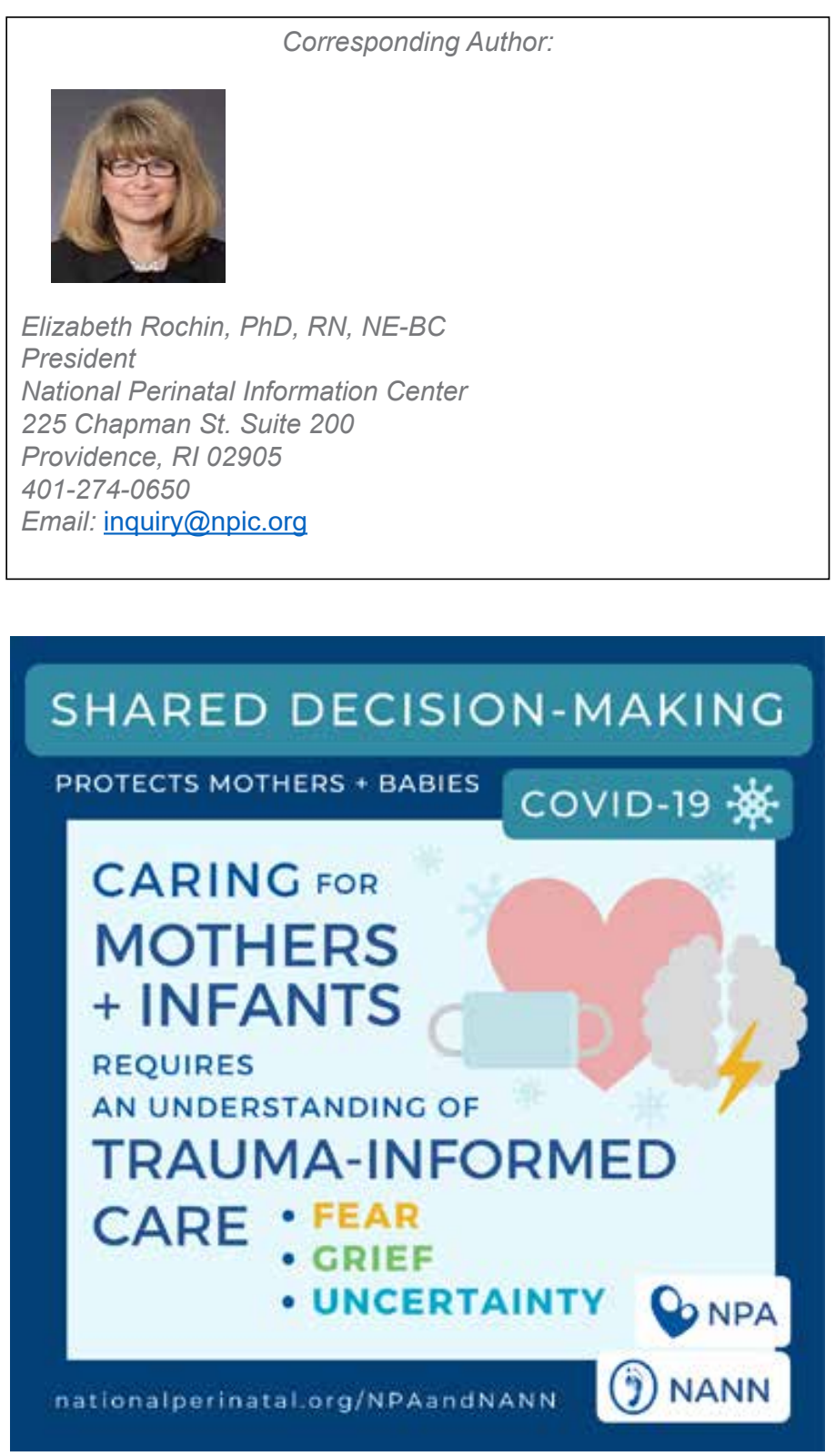